\title{
Gedenken an Prof. Dr. rer. nat., Dipl.-Psych. Ernst Timaeus
}

HerausgeberInnen und Redaktion der Zeitschrift Gruppendynamik und Organisationsberatung trauern um ihren langjährigen beratenden Herausgeber Prof. Dr. Ernst Timaeus, der im August dieses Jahres verstarb.

Er lernte zunächst im väterlichen Betrieb in Goslar das Glaserhandwerk, er holte dann das Abitur nach und studierte in Göttingen Psychologie, wo er zum Dr. rer. nat. promovierte. Ab 1962 war er maßgeblich am Aufbau des Instituts für Sozialpsychologie an der Universität zu Köln beteiligt, wo er wohl als erster in Deutschland Untersuchungen über Versuchsleitereinflüsse durchführte. Er nahm in den folgenden Jahren den Ruf auf eine Ordentliche Professur für Sozialpsychologie an der Gesamthochschule Essen an. Dort lehrte er fast bis zu seinem Tode.

Seine Forschungsschwerpunkte umfassten Themen zur empirischen Grundlagenforschung und deren Anwendung, pragmatische Probleme des sozialen Lernens sowie Studien zur Gesundheitsfürsorge von Jugendlichen.

Er gehörte seit 1973 zu den beratenden Herausgebern der Zeitschrift Gruppendynamik und Organisationsberatung und trug durch seine regelmäßige, engagierte und kritisch konstruktive Arbeit zur Weiterentwicklung der Zeitschrift bei.

Er hat in den Jahren seiner Herausgeberschaft seltener als Autor und Editor zur Zeitschrift beigetragen, sondern vor allem durch Manuskriptbegutachtungen und durch Anregungen zu Themenschwerpunkten.

Wir danken ihm für die lange Wegstrecke, die wir gemeinsam mit ihm gehen durften.

Jörg Fengler und Susanne Nussbeck 